\title{
Technical-economic analisys of the solvent-method optimization of Origanum vulgare essential oil extraction based on technical and quality criteria
}

\author{
Lenin Trujillo-Echeverria ${ }^{1}$ (i) - Marco Vinicio Lara Fiallos ${ }^{1}$ (D) . Juan Carlos de la Vega Quintero ${ }^{1,2}$.

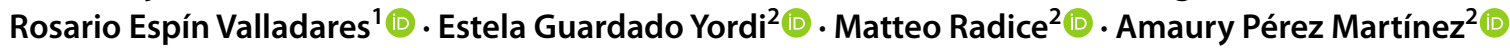

Received: 24 August 2020 / Accepted: 24 November 2020 / Published online: 2 December 2020

(c) Springer Nature Switzerland AG 2020

\begin{abstract}
The aim of the present research was oriented to study the effect of solvent polarity, solute-solvent ratio, selection of the solvent method and particle size on the performance of the Origanum vulgare extraction, its parameters in reference to quality physicochemical criteria and its technoeconomic feasibility. A completely randomized experimental design with $\mathrm{A} \times \mathrm{B}$ factorial arrangement was used, with the purpose of establishing adequate data processing that will serve as a basis for diagrams that interpret the kinetics of an extraction process at defined conditions (pressure and temperature), in intimate relation to the polarity of the solvent. The application of technical standards in the characterization of plant matter and final product has been considered, physically and chemically analyzing its main properties (humidity $10.7453 \%$ wet basis, ethereal extract $1.833 \%$, refractive index $1.4774-1.4790$, acidity index $0.4632-0.7628 \%$ and density $0.9169-0.9396$ ). The described actions affirm the detailed analysis about the extraction process and the operative variables that affect the phenomenon, focused on the generation of experimental mathematical monograms and models that reflect the characteristics of obtaining the essential oil of $O$. vulgare, which contributes to the reduction of the production conflicts associated with the extraction (the type of solvent, particle size, solute-solvent ratio, environmental pollution, etc.) of essential oils, with lower costs, best strategies and higher yields. Two kinetic models were successfully used to describe the phenomenon produced by hydrodistillation in 0 . vulgare essential oil.
\end{abstract}

Keywords Essential oils · Origanum vulgare · Mathematical models · Operation costs · Yields · Quality

\section{Introduction}

Nowadays, the constant technological advances and industrial needs maintain the constant search for new processes that minimize the problems associated with the extraction of essential oils or essences, with lower costs and higher yields. In this sense, it has been shown that in order to carry out the essential oil extraction process it is necessary to analyze production costs, solvent selection based on the final extract ratio, energy synergy (in reactions and separation), redistribution of flows, besides studying the intimate relationship with the availability of ethereal extract of the different vegetative species [1]. On the other hand, these percentages can be significantly affected due to the use of different solvents whose polarity ratio is variable, consequently, the extraction processes differ in their productivity results despite applying similar methodology. However, today it can be mentioned that

\footnotetext{
$\triangle$ Marco Vinicio Lara Fiallos, mvlara@utn.edu.ec; Lenin Trujillo-Echeverria, Irtrujilloe@utn.edu.ec; Juan Carlos de la Vega Quintero, jcdelavega@utn.edu.ec; Rosario Espín Valladares, rcespin@utn.edu.ec; Estela Guardado Yordi, e.guardadoy@uea.edu.ec; Matteo Radice, maradice@uea.edu.ec; Amaury Pérez Martínez, amperez@uea.edu.ec|'1 Universidad Técnica del Norte, Ave. 17 de Julio 5-21, Ibarra, Ecuador. ${ }^{2}$ Universidad Estatal Amazónica, km 2 1/2 Via Puyo a Tena, Puyo, Pastaza, Ecuador.
} 
there are other parameters to consider apart from those already mentioned, such as they are technical and quality criteria, where prevail techno-economic principles, green chemistry [2], the strategic alternatives in the selection of the solvent-method due to the improvement of the performance by cosolvencia and polarity of the solvents [3]. Quality criteria of the extracts, regarding particularly its physicochemical characteristics, it is estimated that this exegesis is a complement to the inclusion of new functions of essential oils in the integration to new products, support to reduce environmental pollution and improve its industrialization. Although some of them have been studied separately, it is convenient to deepen their study [4].

There are several species that have been called orégano, the most characteristic being the genus Origanum [5]. According to studies $O$. vulgare L. have multiple uses within the different manufactures such as: seasoning in the food industry, flavoring extracts in cosmetic manufacturing, production of essential oils and oleoresins in oil manufacturing. On the other hand, according to alternative medicine sources, the different species of Orégano are used to mitigate the effects of some diseases such as acne, asthma, indigestion, headache, Alzheimer's, among others $[6,7]$. Currently, several spices, specifically from the Lamiaceae family, to which oregano belongs, have been evaluated for their antioxidant and food preservative capacity, thus increasing their importance in the food industry as an alternative to synthetic additives $[8,9]$. Being these active principles those that manage to act in one or several of the stages of the oxidative sequence and, although its antioxidant activity is associated with several mechanisms, its high reactivity against active free radicals is considered the main mechanism .

Several applications of $O$. vulgare essential oil have been investigated. In recent years authors such as Karaman et al., López-Rivera et al. and Oniga et al. [10-12] have ratified antimicrobial, antifungal, antioxidant and anti-radical properties. As for trade, this product is considered to have a strategic role to produce primary and secondary products of mass consumption, this type of essential oil has high prices, even reaching values of $\$ 40.00$ per unit (15 mL).

Each year, the consumption of essential oil increases by approximately $8-10 \%$. It occurs not only in Ecuador, but also in other producing countries, such as India, Thailand, United States, Haiti, among others [13]. Such a trend is triggered by the increase in innovation needs for the industry. It is also driven by the tendency of consumers to change the use of materials containing synthetic compounds by natural ones; thus, increasing the demand for essential oils.

In particular, the oil industry has not innovated, since it uses the use of traditional methodologies such as hydrodistillation and pressing in its broad spectrum, without considering the existence of other alternative processes such as the use of solvents or supercritical fluids [8]. Each technique has advantages and disadvantages. Although in the extraction development, low yields are the daily theme of the producers, due to the high production costs, the use of correct solvents, their wastes and their contamination with the environment, there are numerous articles that deal with the yield and composition of the essential oil obtained from oregano through different recovery techniques; however, they do not analyze the kinetic model that describes the extraction process itself, producing a limited interpretation of yield maximization, focused on their productive deficit.

Knowing that the performance of the process is not governed by a continuous behavior because the speed of the process decreases rapidly, the kinetic study is governed mainly by three controlling phenomena: (a) an in situ vaporization in the interface of the film formed by the plant material and the surrounding steam; (b) the diffusion of the oil in concavity of the adjacent steam stream, produced by the convection exerted by the steam in the solute, and its immediate transport abroad; and (c) an exudation (or evacuation) of the essential oil from inside the glandular trichomes, through its cuticle, to the surface film of the plant material [14]. With these premises, the present study refers to establishing kinetic models for the oil industry in order to promote the extraction process optimization. The study focused productive technician benefits considering the behavior of the raw material and the variables that govern the process, such as solvent polarity as a strategy in choosing the solvent-method, techno-economic feasibility, green chemistry promoting the reduction in environmental pollution and quality in function of its physicochemical characteristics.

\section{Materials and methods}

\subsection{Physicochemical parameters of Origanum vulgare}

The humidity content was determined with the AOAC method 1990/964.22, using an infrared balance (of trademark AE Adam, model of the PMB 53 equipment, with a capacity of $50 \mathrm{~g}$ per sample and a readability of $0.001 \mathrm{~g}$ ). Approximately $5.0 \mathrm{~g}$ of sample was weighed on the balance that determines humidity until reaching a constant weight. The weight loss was considered as the moisture content and the dried residue of the species was considered as dry matter.

The crude fat was determined using the AOAC Official Method 920.39 method, a 6-position (of trademark Velp, SER-148 model) solvent extraction system per solvent 
was used adapted to Randall method, extraction was performed by immersion the sample in the boiling solvent, followed by a rinsing phase with hot solvent. Then all the solvent is evaporated and recovered in a condenser. The calculation of the total fat content was done gravimetrically after drying the extract.

The statistical treatment of the data was carried out using the statistical package IBM SPSS Statistics 25 and RStudio, by which the descriptive statistic (mean and standard deviation) were determined. The assumption of normality of the data was tested by the Shapiro-Wilks test and the homogeneity of the variance was evaluated using the Levene test. Pearson correlations were made between the physicochemical compounds of the raw material (Origanum), besides to the analysis of ADEVA with factorial interaction was performed, followed by multiple Tukey comparisons, to determine if there is a significant difference between the factors under study at a level of $5 \%$ significance. Data are reported as average \pm standard deviation.

\subsection{Plant material and essential oil extraction conditions}

Plant raw material has been purchased from a local market in Ibarra (Ecuador). Hydrodistillation and leaching extraction (by the Randall method) were performed including the following parameters: (i) $O$. vulgare samples weight from 25 to $50 \mathrm{~g}$, (ii) particle size between 0.3 and $0.5 \mathrm{~mm}$; (iii) solute-solvent ratios (w/v): 1: 5 1:15 and 1:25. The essential oil yield $(\mathrm{v} / \mathrm{w})$ was recorded after the hydrodistillation time $120 \mathrm{~min}$, the data was measured every $10 \mathrm{~min}$ until the maximum time (120 $\mathrm{min}$ ) was reached.

For the ratio 1:15 (w/v) $50 \mathrm{~g}$ of plant material (O. vulgare) and $750 \mathrm{~mL}$ of solvent (water, ethanol, and chloroform) were used. While for 1:25 (w/v) the ratio of plant matter and solvent was considered, respectively.

Solvent extraction was performed using soxhlet equipment by means of the Randall method [15], ethanol and chloroform were selected as solvents. The above-mentioned procedure is a modification of the standard Soxhlet extraction: in Randall, the extraction is made by immersion of the sample in the boiling solvent. This step is followed by a rinsing phase with hot solvent. Then, all the solvent evaporates, and it is recovered in a condenser. The calculation of the total fat content follows gravimetrically after drying the extract, generating as the only data the final extract (dry) of the process and not the measurement over time.

Then, in each treatment, the necessary data were taken to calculate the oil accumulation speed and the performance of the process. To determine the total accumulation rate, the amount of essential oil obtained in milliliters was measured and divided by the duration of the extraction, as reflected in Eq. 1:

Extraction speed $=\frac{(m L \text { essential oil obtained })}{(\text { total time of extraction })} * 100$

Regarding the yield, the same amount of essential oil obtained in milliliters was used, measured for the extraction speed, but divided by the amount of raw material used, expressed in grams as shown in Eq. 2:

Yield $=\frac{(m L \text { essential oil obtained })}{(\text { g plant } \text { material })}$

\subsection{Kinetics models of hydrodistillation and solvent extraction}

The hydrodistillation and solvent kinetics of oregano essential oil were modeled using two models (Table 1):

For Ponomarev model: q0-the initial amount of essential oil, qi-the oil content after the period $t, b$ hydro-distillation coefficient. For Generalized logistic model: $(C)$ is the constant of the equation, $(K)$ is maximum oil concentration $(\mathrm{mL}),(A)$ is the lower asymptote $(\mathrm{mL})$ (initial concentration of oil), (B) is growth rate (min1), (v) represents the maximum growth of asymptote.

According to Stanojevi et al. [18], to model the kinetics of the hydrodistillation process of essential oils based on the Ponomarev model, certain conditions must be considered, like what: He plants particles are isotropic, equal in size, shape and initial oil content and do not change their size and shape during the hydrodistillation. The essential oil is considered as a pseudo-component.

The essential oil concentration on the external surfaces of the plant particles at any moment during the hydrodistillation is zero because of its instantaneous washing from the surfaces; and then to model hydrodistillation no chemical reaction, it is done by Fick's second law of one-dimensional unsteady-state diffusion:

To solve Eq. (1), the following assumptions at the level of plant particles in the suspension should be made and integrate the equation:

Table 1 Kinetics models of essential oil extraction from O. vulgare

\begin{tabular}{lll}
\hline Model & Second kinetics equation & References \\
\hline $\begin{array}{c}\text { Ponomarev model } \\
(\text { Model A) }\end{array}$ & $\frac{(q 0-q i)}{(q 0)}=b+k t$ & {$[16]$} \\
$\begin{array}{c}\text { Generalized logistic } \\
\text { model (Model B) }\end{array}$ & $y(t)=A+\frac{(K-A)}{\left(C+e^{(-B(t)} \frac{1}{v}\right)}$ & [17] \\
\hline
\end{tabular}


$\frac{\partial C}{\partial \dot{t}}=D \frac{\partial^{2} C}{\partial x^{2}}$

To calculate the parameters of an equation, use its linearized form:

$\ln \frac{(q)}{(q 0)}=\ln (1-b)-k t$

This approach was used to determine the leaching coefficient and the slow extraction coefficient. The empirical equation of the monomials or Ponomarev model: This model assumes that during the period of slow extraction there is also a linear dependence between the normalized mass of the expelled substances $\frac{(q 0-q i)}{(q 0)}$ and the time t:

$\frac{(q 0-q)}{(q 0)}=b+k t$

where: (b) is the discharge coefficient and ( $k$ ) is the linear dependence of the direction. The leaching coefficient is a measure of the mass of the extracts that dissolve as the plant material is immersed in the solvent, that is: $b=\left(\frac{(q 0+q i)}{(q 0)}\right)_{t=0}$, parameter $\mathrm{k}$ is the dissolution rate of extractive substances in relation to its initial mass during the slow extraction period, so it can considered as the specific slow extraction speed. The expression mentioned above is equivalent to the percentage of the yield of the essential oil obtained at the end of the process.The term, $q 0$ represents the availability of extract at $t=0$, which is evaluated based on the initial physicochemical characteristics of the raw material; while qi constitutes the differential of the volume of oil remaining in a certain interval of time $(\mathrm{t})$. The expression mentioned above shows the performance of the essential oil obtained in each phase of the process.

On the other hand, it was used the generalized logistic function or curve, also known as the Richards curve, originally developed for population growth, biological modeling, neural networks, etc. [17], is an extension of the logistic or sigmoid functions, which allows more flexible curves.

The modeling of the extraction kinetics was based on a non-linear, in order to predict and compare the interactions between the independent variable (time) and the response variables (kinetic parameters); The mathematical method allows to determine the maximum oil concentration $(\mathrm{K})$, the initial extraction speed $(t)$, essential oil concentration at any time $(\mathrm{Y})$ and the extraction kinetics constants ( $\mathrm{B}$ and $\mathrm{v}$ ).

The relationship between the conditions of the extraction process and the proposed models is evidenced, since there is an availability ( $\mathrm{q} 0$ and $\mathrm{A}$ ) of initial extract (plant matter) and an extraction differential (volume of essential oil) with respect to time $(t)$ that loses the raw material due to the incidence of the extraction parameters (b, k Ponomarev model and $B$, v generalized logistic function).

\subsection{Experimental design}

For the statistical analysis, a completely randomized experimental design (DCA) with AxB interaction was used, considering the variation of the $R$ factor as set out by $[19,20]$, in addition to identifying the levels of consideration for the two factors under study (Table 2).

In order to establish the kinetic model, the extraction time (min) was used, Extraction speed ( $\mathrm{mL} / \mathrm{min}$ ) and Yield (\% v/w) as axes of the extraction process.

The results obtained were subjected to an analysis of variance $(p<0.05)$, thus determining the statistical significance of the factors on the response variables using the Tukey test (5\%).

\subsection{Quality parameters of the 0 . vulgare essential oil}

The acidity index was obtained using the methodology of ISO 1242:1999, which expressed by the number of milligrams (mg) of $\mathrm{KOH}$ necessary to neutralize the amount of fatty acids contained in 1 gram of oil essential. Density was carried out using the pycnometer method (under the norm, ISO 6883) which is based on the quotient between the mass of the liquid evaluated or problem and the volume of the pycnometer related to the known solution (water) and the weight of the pycnometer for both solutions.

The refractive index was evaluated which refers to the measure of purity of a substance, in addition to the fact that under this parameter the extract meets certain conditions in relation to a comparison standard: the analysis was performed according to the protocol described in ISO $\mathrm{R}$ 280:1998 "Determination of the refractive index of Essential Oils", which uses a brand refractometer with temperature control to measure the translucency (difficulty or ease of letting light into the liquid matrix) of the essential oil.
Table 2 Factors and levels of the extraction process

\begin{tabular}{llllll}
\hline Evaluated factors & & & & \\
\hline Factor R: Solute-solvent Ratio & Factor S: Solvent polarity & R2 & $1: 15$ & S1 & Water \\
& & R2 & $1: 15$ & S2 & Ethanol \\
& & R3 & $1: 25$ & S3 & Chloroform \\
\hline
\end{tabular}




\subsection{Production cost analysis.}

In order to consolidate the proposed methodology was carried out an analysis framed in their advantages and disadvantages, as well as the application of the cost per process methodology [21], considering the accumulation of manufacturing costs by department; With zero initial and final production inventories, that is, a proportional relationship is established between the resources (direct and indirect manufacturing) with the stages of the oregano oil extraction process; consequently, formulas used in the cost methodology were:

Production costs $=$ M.P.D + M.O.D + C.I.F

Conversion costs $=M . O . D+C . I . F$

Total costs $=C . P+$ Operating expenses

where in: M.P.D(Direct raw material), M.O.D(Direct Labor cost), C.I.F(Indirect manufacturing costs), and C.P(Production cost).

It is important to highlight that in the key stages of the process (cost centers), there are identifiable resources in these (direct materials, inputs, among others.) Which constituted the direct cost of the main product. However, there are indirect manufacturing costs, which originate directly in the key stages and will therefore be assumed, as well as the productive costs versus the $\%$ of the yield was taken to establish the comparison of costs with the use of the different solvents.

\section{Results and discussion}

\subsection{0. vulgare essential oil physicochemical characterization}

The average results of the characterization of oregano samples, physicochemical analysis of moisture and ethereal extract; They are shown in table 3:

According to the obtained results, it can be indicated that the moisture content (\% wet basis (wb) and ethereal extract of $O$. vulgare, records a behavior as reported at the time by [22], and the near and / or similar value to that found by [23] 1-2\% ethereal extract. This behavior between the variables expresses that the reaction of moisture to fat content tends to behave inversely proportionally (Pearson, $r=$ $-0.999, p<0.05)$.
Table 3 Samples data

\begin{tabular}{lll}
\hline Samples & Wet basis $^{a}(\%)$ & Ethereal extract $^{b}(\%)$ \\
\hline O. vulgare & $10.745 \pm 1,010$ & $1.833 \pm 0.031$ \\
\hline
\end{tabular}

${ }^{a}$ Humidity: Wet basis (wb), ${ }^{b}$ Ethereal extract: crude fat

\subsection{Determination of the extraction kinetics of 0 . vulgare essential oil}

\subsubsection{Hydrodistillation}

Table 4 show the results of the oregano oil extraction process using water as a solvent, at a ratio of 1:15 and $1: 25 \mathrm{w} / \mathrm{v}$, respectively.

Below are the results of the kinetic parameters expressed in extraction curves (Fig. 1), obtained by hydrodestilation in 1:15 and 1:25 w/v ratios respectively, which exhibit a trend similar to that described by [24], who indicate that the extraction process can be represented in several phases.

Four phases are evident, which present a physical sense according to the authors as described below:

Phase 0 This phase indicates the initial time it takes for the extraction solution to reach the boiling temperature to obtain the aqueous extract or hydrolat.

Phase $1 \mathrm{lt}$ is a preliminary phase where the extraction of the essential oil is evidenced in an accelerated way, until reaching approximately $76 \%$ of the total yield of the process.

Phase 2lt is represented by an exponential curve that increases, where the remaining $24 \%$ of the final performance of the process is obtained. During this stage, the oil volatilizes rapidly and mixes with the water vapor, generating possible losses.

Phase 3: It is represented by a horizontal line that marks the end of the extraction process, where no more oil is obtained and a constant performance over time is evidenced.

On the other hand, the yields of the essential oils obtained were slightly significant to those reported in the literature and this can be attributed to the extraction technique, variety, cultivation methods, solute-solvent ratio, geobotanical conditions: climate, altitude, type of floor, luminosity, etc. [25].

Regarding the extraction time, the data obtained show significant differences when compared with those of the literature, which were 3-4 $\mathrm{h}$ according to [7], $2 \mathrm{~h}$ 36 min according to [20] and 120 to $180 \mathrm{~min}$ according [26]. It can be inferred with the aforementioned that depending on the variety of raw material, solute-solvent ratio etc., short times that can go from 30 min can be obtained [27] to $60 \mathrm{~min}$ [28], this related to the way 
Table 4 Samples data

\begin{tabular}{|c|c|c|c|c|c|c|}
\hline \multicolumn{3}{|l|}{$(1: 15)$} & \multicolumn{4}{|l|}{$(1: 25)$} \\
\hline Time (min) & $\mathrm{EO}^{a}(\mathrm{~mL})$ & Speed $^{b}(\mathrm{~mL} / \mathrm{min})$ & Yield (\%) & $\mathrm{EO}^{a}(\mathrm{~mL})$ & Speed $^{b}(\mathrm{~mL} / \mathrm{min})$ & Yield (\%) \\
\hline 0 & 0.000 & 0.000 & 0.000 & 0.000 & 0.000 & 0.000 \\
\hline 10 & 0.000 & 0.000 & 0.000 & 0.000 & 0.000 & 0.000 \\
\hline 20 & 0.100 & 0.001 & 0.240 & 0.100 & 0.001 & 0.250 \\
\hline 30 & 0.300 & 0.003 & 0.600 & 0.300 & 0.003 & 0.620 \\
\hline 40 & 0.600 & 0.005 & 0.990 & 0.500 & 0.004 & 0.930 \\
\hline 50 & 0.800 & 0.006 & 1.350 & 0.700 & 0.006 & 1.240 \\
\hline 60 & 0.900 & 0.008 & 1.650 & 0.900 & 0.007 & 1.580 \\
\hline 70 & 1.100 & 0.009 & 1.900 & 1.000 & 0.008 & 1.780 \\
\hline 80 & 1.200 & 0.010 & 2.080 & 1.100 & 0.009 & 1.950 \\
\hline 90 & 1.200 & 0.010 & 2.200 & 1.200 & 0.010 & 2.070 \\
\hline 100 & 1.300 & 0.011 & 2.300 & 1.200 & 0.010 & 2.160 \\
\hline 110 & 1.300 & 0.011 & 2.360 & 1.200 & 0.010 & 2.220 \\
\hline 120 & 1.300 & 0.011 & 2.380 & 1.200 & 0.010 & 2.250 \\
\hline
\end{tabular}

${ }^{a}$ EO: Essential oil, ${ }^{b}$ Speed: Extraction speed
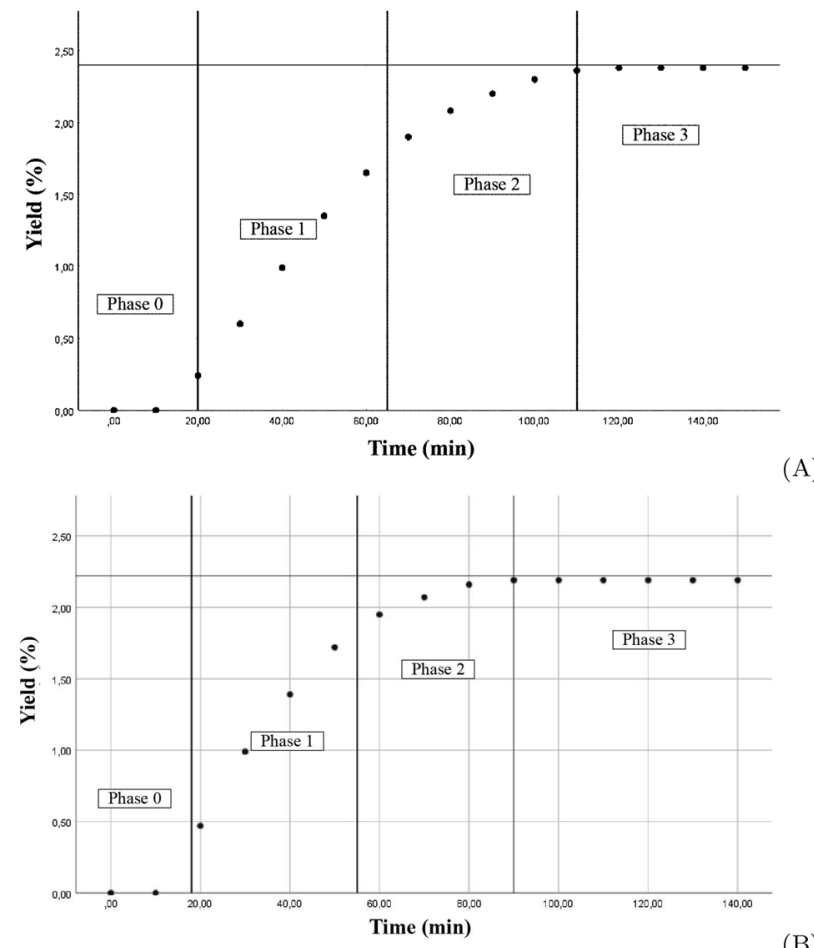

(B)

Fig. 1 Extraction kinetics of $O$. vulgare in ratio (A) Kinetics during hydrodistilation extraction in ratio $(1: 15 \mathrm{w} / \mathrm{v})$ and $(\mathrm{A})$ Kinetics during hydrodistilation extraction in ratio $(1: 25 \mathrm{w} / \mathrm{v})$ heat and mass transfer is performed to achieve thermal equilibrium.

Finally, concerning the extraction rate, values of extraction rates of $0.011 \pm 0.002$ y $0.008 \pm 0.004(\mathrm{~mL} / \mathrm{min})$ were reached, in both solute-solvent ratios $(1: 15,1: 25 \mathrm{w} / \mathrm{v})$ respectively, however, even though the extraction rate is a direct factor that influences In the extraction process, no bibliographic references were found for this parameter. However, authors such as [19] they postulate in their research about the optimization of the extraction process of Lippia graveolens, an extraction rate of 0.0053 (g/mgAG $\min )$.

\subsubsection{Leaching extraction}

A total of 12 samples were evaluated for leaching, where the first group in triplicate (6) were for ethanol and the rest for chloroform, Once the extraction process was completed, the extract was quantified, resulting in the Table 5:

Within the literature review, publications on these determinations for $O$. vulgare essential oil using ethanol as a solvent are almost nil, although within this framework the lack of literature makes data analysis difficult, authors such as [29] analyze the performance of the essential oil of oregano using different extraction methods (including ethanol), concluding in their work, that the process

Table 5 Samples data

\begin{tabular}{lllllll}
\hline Ethanol & & & & & \multicolumn{2}{l}{ Chloroform } \\
\cline { 1 - 1 } Ratio $(\mathrm{w} / \mathrm{v})$ & Time $(\mathrm{min})$ & Yield $(\%)$ & Speed $(\mathrm{mL} / \mathrm{min})$ & & Yield $(\%)$ & Speed $(\mathrm{mL} / \mathrm{min})$ \\
\hline $1: 15$ & 120 & $2.54 \pm 0.003$ & 0.0003 & & $2.443 \pm 0.0006$ & 0.0004 \\
$1: 25$ & 120 & $2.52 \pm 0.003$ & 0.0001 & & $2.403 \pm 0.0006$ & 0.0002 \\
\hline
\end{tabular}


is complex and expensive, where a considerable amount of oleoresin similar to that obtained in the experimental phase is obtained (Fig. 2).

Although the significance found in each method analyzed is evident, the literature review indicates the lack of comparisons in the process of extracting essential oils using chloroform as a solvent, but rather extraction methodologies focused on other processes such as the one described by [30] which analyze the molecular method reflected in DNA extraction; using chloroform as an extracting agent.

Finally, from the results obtained from the different extraction methodologies, the Shapiro-Wilk test and the Levene test were performed to verify the assumption of normality $(p=0.54)$ and homoscedasticity $(p=0.17)$ respectively. In the analysis of variance, as in graph 4 , the significant differences are evidenced both for factor A (solute-solvent ratio), factor B (Solvent "polarity") and their interaction $A \times B$ (Solvent-solvent ratio and solvent in base to polarity); when $F 0>F($ Tabular).

The Pareto diagram reveals the direct influence of the factors dependent on the extraction process ( $A$ and $B$, as well as the parameters responsible for it (Fig. 3); when examining the statistic in a comparative way, finding significant differences when evaluating the performance variable in relation to the different methodologies used in the extraction process. Against this, the differences found indicate that the solute-solvent ratio and solvent polarity directly interfere with the extraction process.

In the Tukey significance test for the yield variable (Table 6), it is you can see that the ratio R2:S2 (solute-solvent $1: 15 \mathrm{w} / \mathrm{v}$ and ethanol) has the highest amount of extract. Comparing with the rest of the treatments it can be observed that there is also a significant difference between them, these differences according to [31] are mainly due to the polarity of the solvent which interacts electromagnetically with the solute, the same authors make reference to the positive effect of the carbon chain

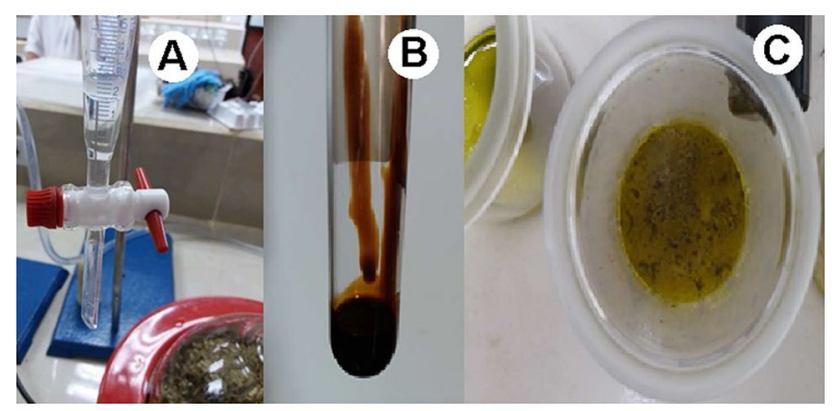

Fig. 2 Oregano essential oils obtained by: a Hydrodistillation, b Extract (oleoresin) obtained in the ethanol extraction process and C)Extract obtained in the chloroform extraction

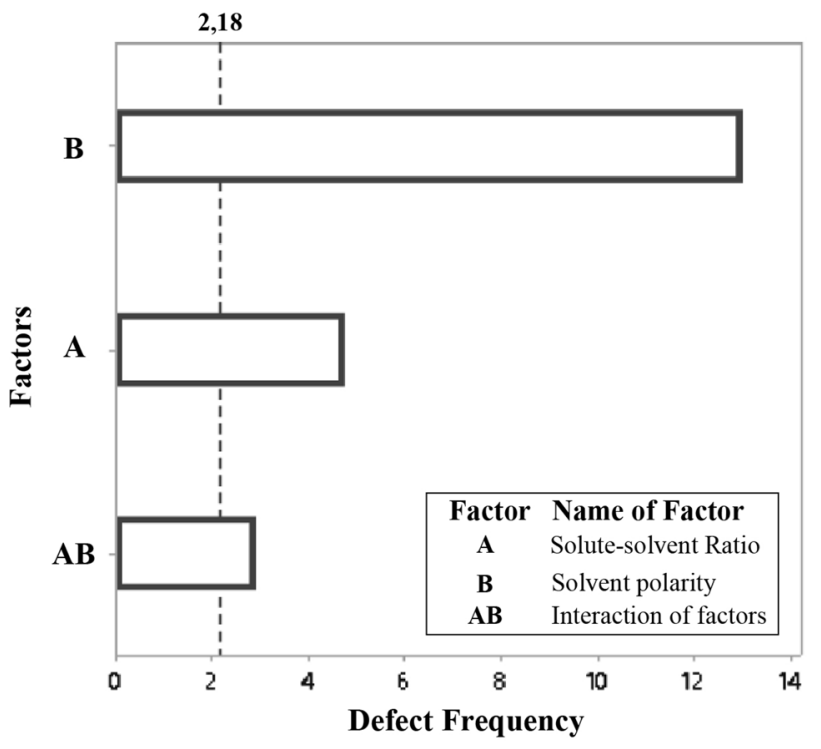

Fig. 3 Pareto diagram for yield

of some polar protic solvents on the final performance of the extraction processes, so that by having this chain in its structure, it extracts more extract compared to water, which is also aprotic solvent. That is why there is a greater extraction using ethanol, then water and finally chloroform which is an aprotic solvent.

On the other hand, when analyzing the kinetic parameter speed of concentration of oregano essential oil ( $\mathrm{mL} /$ min), which was evaluate by analysis of variance and Kruskal-Wallis test (Fig. 4). The results report statistical significance for the solvent factor ( $p$-value $=0.0032$ ), in addition to exposing the effects found in the comparison between treatments (figure), once the Kruskal-Wallis test is applied, the differences found are grouped into three groups; where it is clearly shown that the S1 treatment (water solvent) turns out to be more efficient compared to the other solvents ( $\mathrm{S} 2=$ Ethanol and $\mathrm{S} 3=$ Chloroform), these contrasts according to [32] are due to the natural physicochemical properties of each solvent, since each one must overcome the intermolecular forces of the solutes to be able to break up them. As reported in Fig. 4, the extraction speed seems to be independent to the solvent

Table 6 Tukey test for treatments in the variable yield $(\% \mathrm{w} / \mathrm{v})$

\begin{tabular}{lll}
\hline Factors & Average (\%) & Groups \\
\hline R2:S2 & 2.540 & $\mathrm{~A}$ \\
R3:S2 & 2.523 & $\mathrm{~A}$ \\
R2:S3 & 2.443 & $\mathrm{~B}$ \\
R3:S3 & 2.403 & $\mathrm{BC}$ \\
R2:S1 & 2.367 & $\mathrm{C}$ \\
R3:S1 & 2.250 & $\mathrm{D}$ \\
\hline
\end{tabular}

SN Applied Sciences A SPRINGER NATURE journa 


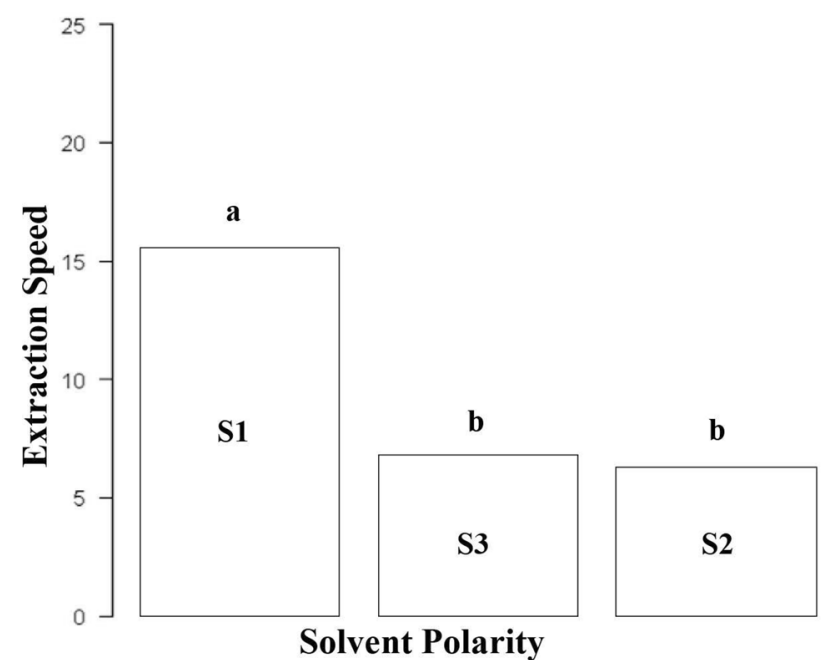

Fig. 4 Kruskal-Wallis test for the rate of accumulation ( $\mathrm{mL} \mathrm{min}$ ) of oregano essential oil developed based on the solvents ( $\mathrm{S} 1=$ water, S2 = Ethanol "ethyl alcohol", S3 = Chloroform y its polarity)

polarity, the faster extraction method seems to be the Soxhlet one, both with a quite polar solvent as ethanol and a very low polar solvent as choloroform

This is how polarity, surface tension, extant and potential energy of the solvent condition the extraction and its parameters, hence the mathematical modeling is proposed for hydrodistillation and not for leaching. However, it can be induced that in terms of performance it is clearly seen that the ratio $\mathrm{R} 2$ that corresponds to $1: 15 \mathrm{w} / \mathrm{v}$ (1 part of plant matter in 15 parts of solvent) and solvent S2 (ethanol) give better results in its final extract, even though in terms of quality and technical criteria (polarity, green chemistry, techno-economics, others) with an addition to innovation, it can be said that the ratio R2:S1 (1:15 w/v and solvent water) turns out to be much more environmentally friendly, it exposes better economic feasibilities and presents greater uses within its applicability (food industry, pharmaceutical, or others).

The results confirmed that different extraction methods provide high yields for specific classes of essential oils. In general, the high polarity solvents achieved the best performance (Figure), unlike the water that presented the lowest performance. In fact, a significant correlation was observed between the polarity of the solvent and the yield ( $r=-0.70, r=-0.82$ ) of the AE of $O$. vulgare in the different relationships: 1:15 and 1:25 w/v respectively (Fig. 5) The dependence of the extraction method and parameters on the different classes of essential oils, waxes or extracts is due to the fact that the solvents promote the partial hydration of the particles and improve the accessibility to the solvent. Furthermore, some plant species occur as complex structures (particle size, composition, others),
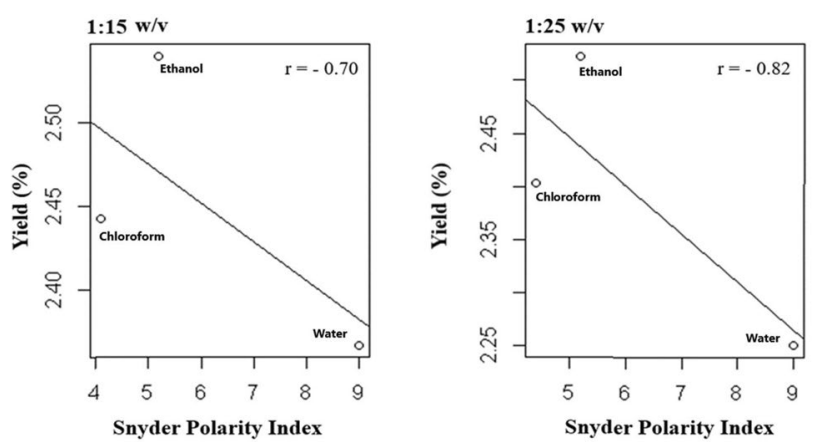

Fig. 5 Correlation between the solvent polarity and yield of O.vulgare in ratio ratio $1: 15$ and 1:25 w/v

so extraction is more difficult and is only possible when the solvent is able to overcome the hydrophobic, van der Waals and ionic forces that exist between lipids and the plant matrix [33].

Generally, steam extraction has been a common process for obtaining essential oils, and green chemistry trends, such as the minimization or non-use of toxic solvents in processes, allow the presentation of preliminary results to optimize the essential oil extraction method. of $O$. vulgare regardless of the performance achieved, but rather due to its qualities and its zero toxicities in its applicability.

\subsubsection{Mathematical modeling of extraction kinetics}

Figure 6 shows the results of the kinetic parameters evaluated in the extraction of the essential oil of $O$. vulgare obtained by hydrodistillation. It is important to note that once the main parameters of the equation have been established, as well as the constants of the kinetic parameters by non-linear regression as a function of time.

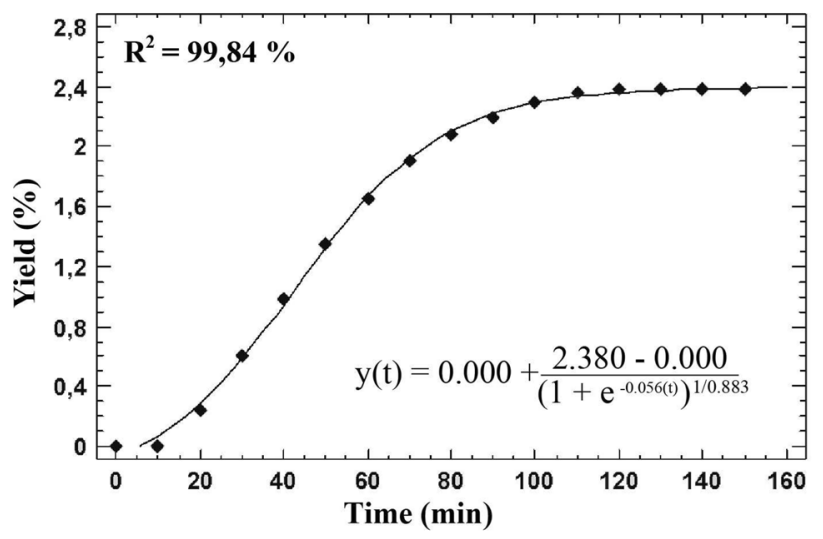

Fig. 6 Kinetics during extraction oil in ratio 1:15(w/v) obtained by mathematics model 
The modeling graphs allows to determine that the kinetic parameters are within the established, thus ratifying the model and therefore its adjustment, that is, they provide information to determine: the average amount of oil in $\mathrm{mL} / \mathrm{g}$ that can be obtained in the first minutes of the process (initial time of accumulation), as well as the maximum amount of oil $\mathrm{mL} / \mathrm{g}$ that can be obtained (final extraction time) at the end of the extraction of the essential oil of $O$. vulgare. A complement to the analysis according to [13] is that in the first phase of the extraction there is a driving force between the solvent which extracts most of the essential oil contained in the plant matter at an accelerated rate of heat and mass transfer; Below is a phase which is much slower than occurs with the external diffusion of essential oil in the extract. These phenomena are typical of a second order process and can be interpreted in the analysis of experimental results.

It should be noted that the equation described above is a real estimate of the extraction process this due to its percentage of variance $R^{2}=99.86 \%$ and its standard error of 0.036 , acceptable values at the time of analyzing the statistic, however it is the first time it is used this function in an extraction process, this given to the articulation of the function with the process itself. However, it is important to mention that in the literature review, it was found that there are several mathematical models of extraction kinetics, several based on Fick's law, empirical modeling, by means of matter balances, first and second order kinetic models [18], in their research propose an analytical modeling for the modeling of hydrodistillation extraction kinetics defined as $\frac{(q 0-q i)}{q 0}=b+k t$ where by curves they plotted $\frac{(q 0-q i)}{q 0}$ versus time, determining two stages that occur in the process; First stage, the oil that is on the surface of the cells (it is easier to extract) and evaporates quickly; Second stage, the diffusion of the essential oil from inside the cells, so the extraction is done more slowly, on the other hand the average value of the goodness of fit criteria for the two models considered is shown below.

Considering that the proportion of the variance explained by the models was high, $99.86 \%$ and $93.89 \%$ respectively (Fig. 7), both models can be considered valid to describe the essential oil production profiles. According to these results, it is concluded that he should not be the main one, much less the only criterion to define if a model is adequate, because the models do not indicate whether the adjustment made is sensitive in terms of biological or chemical coherence. High values of can be observed in models with limited predictability.

As the SCT (sum of square treatments) is always the same (52.236) for both models, and the value of the SCE (sum of square experiments) depends exclusively on the good fit of the model; in this case 51,468 for the

\section{Generalized Logistic Model}

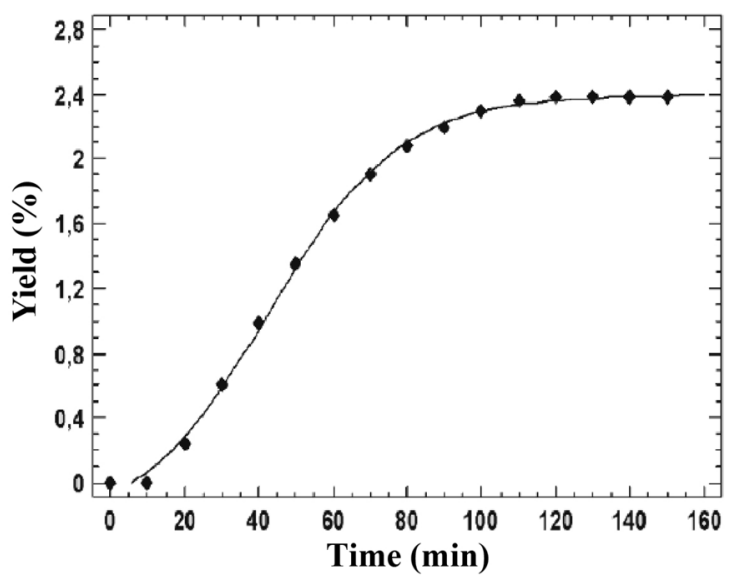

Ponomarev model

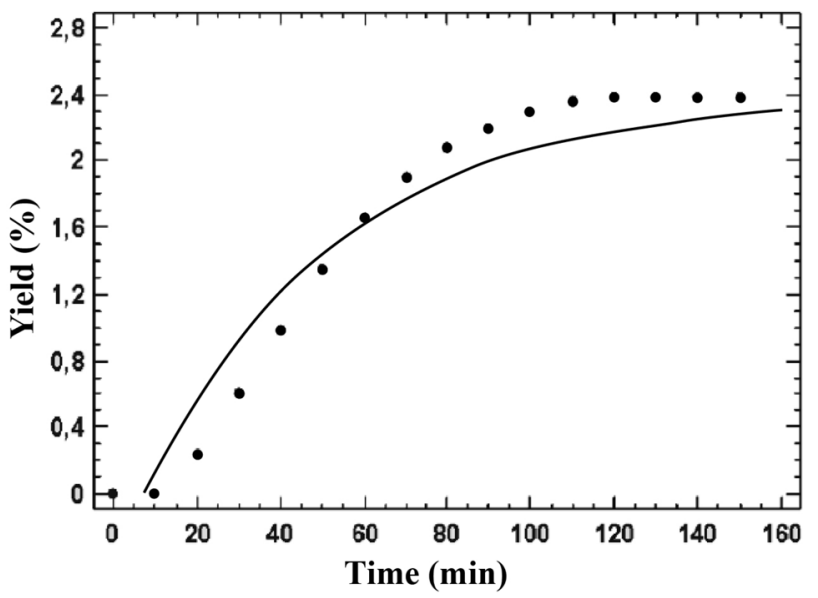

Fig. 7 Cumulative production of essential oil by Ponomarev and logistic models for the solute-solvent ratio $(1: 15 \mathrm{w} / \mathrm{v})$

Ponomarev model and 52.218 of the proposed logistics. It is inferred that the Logistic model was the one that best represented the data set by offering the lowest $\mathrm{SCE}$, which is used to estimate the CME (mean error squares) 25.734 Ponomarev and 17.406 Logistics. Although both criteria balance the change in goodness of fit, evaluated by the sum of squares, with the change in the number of parameters (16 to 14 ) respectively, the values obtained allow us to deduce that the logistic model was the best in explaining the extraction kinetics (Oil yield $=2.38 \%$ and Extraction time $=120.17 \mathrm{~min}$ ). If according to the terms of goodness of the models to describe the kinetics of extraction are very variable between experiments, it makes necessary its evaluation in different conditions and with a wide variety of relationships, allowing to choose the best model for each situation and not the indiscriminate use of A single model. 
Table 7 Quality indicators of O. vulgare essential oil

\begin{tabular}{lll}
\hline Samples & $1: 15(\mathrm{w} / \mathrm{v})$ & $1: 25(\mathrm{w} / \mathrm{v})$ \\
\hline Density $(\mathrm{g} / \mathrm{mL})$ & $0.939 \pm 0.021$ & $0.917 \pm 0.014$ \\
Refraction index & $1.4789 \pm 0.0003$ & $1.4774 \pm 0.0005$ \\
$\begin{array}{c}\text { Acid index (\%) (as phe- } \\
\text { nolic acid.) }\end{array}$ & $1.000 \pm 0.265$ & $0.573 \pm 0.015$ \\
\hline
\end{tabular}

\subsection{0. vulgare essential oil parameters.}

Table 7 shows the results of the characterization of the essential oil obtained from hydrodistillation extraction, where the results for density, refractive index, and acidity index for each of the extracts are first indicated.

Density results are among the ranges reported by the literature as found by [28]) with a density of $0.9132 / \mathrm{mL}$ and for [29] with $0.9117 \mathrm{~g} / \mathrm{mL}$, they do not present significant differences. Unlike the refractive index, Paucar et al. (2015) states that the physicochemical characteristics of the solvent are distributed in a dispersed manner in the cellular structure (greater or lesser concentration in parts of the plant matter) [34], which produces a lack of contact between its bonds making it possible to establish the same intermolecular force in The component to be extracted and having less attraction between them, produces the passage of light in greater or lesser quantity and therefore the variation of this parameter. On the other hand, the behavior of the acidity index is due to the fact that oils with a predominance of unsaturated fatty acids are susceptible to chemical or enzymatic hydrolysis, catalysis and volatilization of these, by action of the aqueous media generated by the disposition of the solvents, according to [35], This generates a non-proportional distribution of fatty acids, inducing an increase or decrease in the acid number in the process of extracting essential oils. Moreover, when choosing the best solvent in terms of quality, it is classified into two groups according to its use, S1 (water) for its physicochemical characteristics, its employ would be based on the food industry, cosmetics, etc., like the solvent S2 (ethanol) except for some uses and S3 (chloroform) due to its qualities, has been classified in pharmaceutical laboratory analytical use and non-food industry.

\subsection{Analysis of the production cost of the extraction process}

Figure 8 shows the cost analysis based on the algorithm presented (costs per process), tabulated based on the production of a $15 \mathrm{~mL}$ unit in $3 \mathrm{~h}$ :

Considering that there is a continuous cost accumulation system, the State of Production, Convection and Total

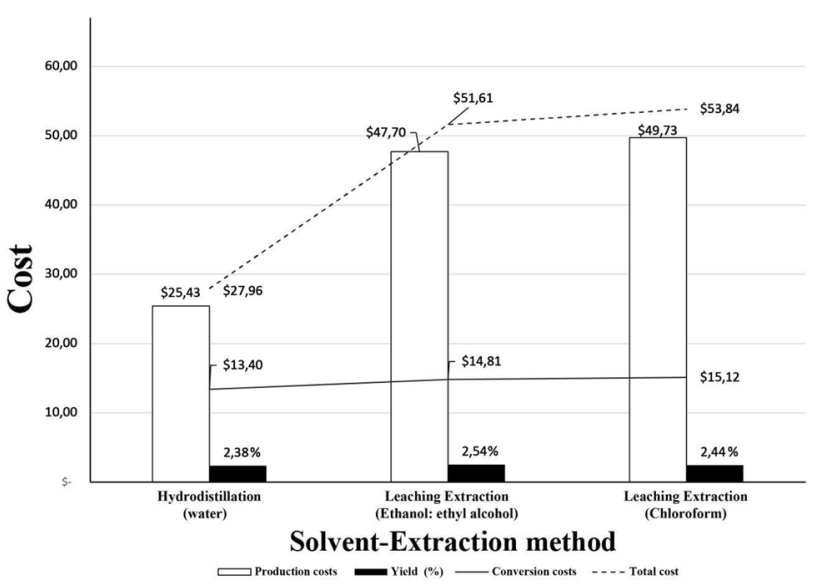

Fig. 8 Cost analysis

Costs is a report that recounts all the economic movement that occurred in the process and of the finished product. Leaching production costs are significantly involved in the hydro-distillation process, despite the difference presented versus the yield obtained. However, it is important to note at this point that despite the differences found in the yield, it is more convenient to produce an essential oil of oregano using hydrodistillation than with the use of solvents, this as awareness of the cost of production per unit $(15 \mathrm{~mL})$ and its assumptions. The extraction kinetics was expressed for hydrodistillation due to its characteristics found within the statistical analysis for the variable rate of accumulation $(\mathrm{mL} / \mathrm{min})$, these conditions generate an average production cost of $\$ 1.69$ (water), $\$ 2.68$ (ethanol) and $\$ 3.50$ (chloroform) per $\mathrm{mL}$ of essential oil extracted.

\section{Conclusions}

It was possible to evaluate, model and optimize the process of extraction of essential oil of $O$. vulgare by modifying variables and input parameters, managing to improve the yields reported in the literature, without affecting the costs of the process. Operating with extraction times of $120 \mathrm{~min}$, solvent-based controlled temperature and with plant material of $10.745 \pm 1.010 \%$ humidity and $1.833 \pm 0.031$ Ethereal Extract, reaching yields of 2.54 and $2.52 \%$ for ethanol, 2.44 and $2.40 \%$ for chloroform and 2.37 and $2.25 \%$ for water in relation 1:15 and 1:25 w/v respectively, proving to be the best obtained by ethanol.

The logistic kinetic model was the one that best represented the experimental results of oregano oil extraction by hydrodistillation $\left(R^{2}=99.86 \%\right)$ compared to the first order kinetic model $\left(R^{2}=93.89 \%\right)$. In terms of quality, solvent $\mathrm{S} 1$ (water) is grouped into the best solvent for food and cosmetologically use, due to its toxicological, 
physicochemical and environmentally friendly characteristics in its productive stages, like the solvent S2 (ethanol) except for some uses, with the differences of S3 (chloroform) which, due to its qualities, has been classified in pharmaceutical and laboratory analytical use. Moreover, S1 (water) is also the cheaper solution.

Accordingly, the green chemistry trends, such as the minimization or non-use of toxic solvents in chemical processes, allows to present preliminary results in order to optimize the extraction method of $O$. vulgare essential oil.

\section{Compliance with ethical standards}

Conflict of interest The authors declare that they have no conflict of interest.

\section{References}

1. Benyoussef EH, Bessah R (2014) Potential of renewable energies integration in an essential oils extraction process. Appl Mech Mater 492:512-523. https://doi.org/10.4028/www.scientific.net/ amm.492.561

2. Wang Y, Li R, Jiang Z-T, Tan J, Tang S-H, Li T-T, Liang L-L, He H-J, Liu Y-M, Li J-T, Zhang X-C (2018) Green and solvent-free simultaneous ultrasonic-microwave assisted extraction of essential oil from white and black peppers. Ind Crop Prod 114:164-172. https://doi.org/10.1016/j.indcrop.2018.02.002

3. Kumar SJ, Prasad SR, Banerjee R, Agarwal DK, Kulkarni KS, Ramesh K (2017) Green solvents and technologies for oil extraction from oilseeds. Chem Cent J 11:1-7. https://doi.org/10.1186/ s13065-017-0238-8

4. Cervato G, Carabelli M, Gervasio S, Cittera A, Cazzola R, Cestaro B (2000) Antioxidant properties of oregano (Origanumvulgare) leaf extracts. J Food Biochem 24:453-465. https://doi. org/10.1111/j.1745-4514.2000.tb00715.x

5. Peter KV (2012) Handbook of herbs and spices. 2nd ed., 591, Woodhead Publishing, Philadelphia, USA, https://doi. org/10.1533/9780857095671

6. Preedy Victor R (2015) Essential oils in food preservation, flavor and safety. 875, Academic Press Imprint, Elsevier Science and Technology Books, UK. https://doi.org/10.1533/9780857095671

7. Torrenegra ME, Matiz GE, Gil J, León G (2015) Actividad antibacteriana in vitro de aceites esenciales frente a microorganismos implicados en el acné. Rev Cubana Farm 49:512-523

8. Salih B, Çelikbçak Ö (2012) Gas chromatography in plant science. Wine Technology, Toxicology and Some Specific Applications, 725, IntechOpen. Rijeka. https://doi.org/10.5772/2517

9. Martínez-Rocha A, Puga R, Hernández-Sandoval L, Loarca-Piña G, Mendoza S (2008) Antioxidant and antimutagenic activities of Mexican oregano (Lippia graveolens Kunth). Plant Foods Human Nutr 63:1-5. https://doi.org/10.1007/s11130-007-0061-9

10. Karaman $M$, Bogavac $M$, Radovanović $B$, Sudji J, Tešanović $K$, Janjušević $L$ (2017) Origanum vulgare essential oil affects pathogens causing vaginal infections. J Appl Microbiol 122:11771185. https://doi.org/10.1111/jam.13413

11. López-Rivera R, Espinosa-Andrews H, García-Márquez E, HerreraRodríguez S (2018) Efecto antifúngico de emulsiones a base de aceite esencial de orégano mexicano (Lippia graveolens), contra Candida albicans. Sal Jal 5:42-45
12. Oniga I, Puşcaş C, Silaghi-Dumitrescu R, Olah N-K, Sevastre B, Marica R, Marcus I, Sevastre-Berghian AC, Benedec D, Pop CE, Hanganu D (2018) Origanum vulgare ssp. vulgare: chemical composition and biological studies. Molecules 23:2077. https ://doi.org/10.3390/molecules23082077

13. Kusuma HS, Mahfud M (2017) Comparison of conventional and microwave-assisted distillation of essential oil from Pogostemon cablin leaves: analysis and modelling of heat and mass transfer. J Appl Res Med Aroma 100:55-65. https:// doi.org/10.1016/j.jarmap.2016.08.002

14. Orio L, Cravotto G, Binello A, Pignata G, Nicola S, Chemat F (2012) Hydrodistillation and in situ microwave-generated hydrodistillation of fresh and dried mint leaves: a comparison study. J Sci Food Agric 92:3085-3090. https://doi.org/10.1002/ jsfa. 5730

15. Bonilla-Méndez JR, Hoyos-Concha JL (2018) Métodos de extracción, refinación y concentración de aceite de pescado como fuente de ácidos grasos omega 3. Corpoica Cienc Tecnol Agropecu 19:645-668. https://doi.org/10.21930/rcta.vol19 num2 art:684

16. Stanojević L, Radulović N, Djokić T, Stanković B, llić D, Cakić M, Nikolić V (2011) The effect of hydrodistillation techniques on yield, kinetics, composition and antimicrobial activity of essential oils from flowers of Lavandula officinalis L. Hem Ind 65:455-463. https://doi.org/10.2298/HEMIND110129047S

17. Koya P, Goshu A (2013) Generalized mathematical model for biological growths. Sci Agropecu 1:42-53. https://doi.org/10.4236/ ojmsi.2013.14008

18. Stanojević LP, Radulović NS, Djokić TM, Stanković BM, llić DP, Cakić MD, Nikolić VD (2015) The yield, composition and hydrodistillation kinetics of the essential oil of dill seeds (Anethi fructus) obtained by different hydrodistillation techniques. Ind Crop Prod 65:429-436. https://doi.org/10.1016/j.indcrop.2014.10.067

19. Flores-Martínez H, León-Campos C, Estarrón-Espinosa $M$, Orozco-ávila I (2016) Optimización del proceso de extracción de sustancias antioxidantes a partir del orégano mexicano (Lippia graveolens HBK) utilizando la metodología de superficie de respuesta (MSR). Rev Mex Ing Quim 15:773-785. https://doi. org/10.1002/aic.11438

20. Tamayo LE, Ramírez SI, López O, Quiroga RR, Espinosa S (2016) Extractos por destilación de Origanum vulgare, Tradescantia spathacea y Zingiber officinale para el manejo de Moniliophthora roreri de Theobroma cacao. Rev Mex Cienc Agríc 7:1065-1076

21. Mitchell M, Vanderbeck EJ (2017) Principios de Contabilidad de Costos, 616. Cengage Learning, Boston

22. Sequeiros N (2017) Deshidratación y elaboración de un condimento en polvo en base a Orégano (Origanum Vulgare L.). Ciencia y Desarrollo 11:83-86. https://doi.org/10.33326/26176 033.2007.11.231

23. Teixeira B, Marques A, Ramos C, Serrano C, Matos O, Neng NR, Nogueira JMF, Saraiva JA, Nunes ML (2013) Chemical composition and bioactivity of different oregano (Origanumvulgare) extracts and essential oil. J Sci Food Agric 93:2707-2714. https ://doi.org/10.1002/jsfa.6089

24. Boukroufa $M$, Boutekedjiret $C$, Petigny $L$, Rakotomanomana $\mathrm{N}$, Chemat $\mathrm{F}$ (2015) Bio-refinery of orange peels waste: a new concept based on integrated green and solvent free extraction processes using ultrasound and microwave techniques to obtain essential oil, polyphenols and pectin. Ultrason Sonochem 24:72-79. https://doi.org/10.1016/j.ultsonch.2014.11.015

25. Stashenko EE, Martínez JR, Ruíz CA, Arias G, Durán C, Salgar W, Cala M (2010) Lippia origanoides chemotype differentiation based on essential oil GC-MS and principal component analysis and PCA. J Sep Sci 33:93-103. https://doi.org/10.1002/ jssc. 200900452 
26. Acevedo D, Navarro M, Monroy L (2013) Composición Química del Aceite Escencial de Hojas de Orégano (Origanumvulgare). InfTecnol 24:43-48. https://doi.org/10.4067/S0718-0764201300 0400005

27. Albado Plaus E, Saez Flores G, Grabiel Ataucusi S (2001) Composición química y actividad antibacteriana del aceite esencial del Origanum vulgare (orégano). Rev Med Hered 12:16-19

28. Tellez-Monzón LA, Nolazco-Cama DM (2017) Estudio de la composición química del aceite esencial de orégano (Origanum vulgare spp) de Tacna. Ingeniería Ind 35:195-205. https://doi. org/10.26439/ing.ind2017.n035.1801

29. Hernández L, Juárez A, Martínez J, Pérez L, Mares E (2016) Aceite esencial de Orégano como potencial nutracéutico. Investigación y Desarrollo en Ciencia y Tecnología de Alimentos 1:443-448

30. Fraga J, Rodríguez J, Fuentes $\mathrm{O}$, Castex M, Fernández-Calienes $\mathrm{A}$ (2004) Comparación entre 5 métodos para la extracción de ADN de triatomíneos: su utilización en la técnica de ADN polimórfico amplificado al azar (RAPD). Rev Cubana Med Trop 56:203-207

31. Ramírez D, Moreno M, Curbelo C, Crespo L (2016) Influencia del tamao de partícula y la velocidad de agitación sobre el rendimiento de pectina. Rev Cubana Farm 50:98-105

32. Masschelein-Kleiner L (2004) Les solvants, Centro Nacional de Conservación y Restauración
33. Bahrami N, Yonekura L, Linforth R, Carvalho da Silva M, Hill S, Penson S, Chope G, Fisk ID (2014) Comparison of ambient solvent extraction methods for the analysis of fatty acids in nonstarch lipids of flour and starch. J Sci Food Agric 94:415-423. https://doi.org/10.1002/jsfa.6449

34. Paucar-Menacho LM, Salvador-Reyes R, Guillén-Sánchez J, CapaRobles J, Moreno-Rojo C (2015) Estudio comparativo de las características físico-químicas del aceite de sacha inchi (Plukenetia volubilis L.), aceite de oliva (Olea europaea) y aceite crudo de pescado. Sci Agropecu 6:279-290. https://doi.org/10.17268/sci. agropecu.2015.04.05

35. Nolazco D, Téllez L, Ccap K (2015) Influencia de la concentración de aceite esencial de orégano (Origanum vulgare L.) en el tiempo de vida en anaquel del aceite de oliva (Olea europea) extravirgen. Ingeniería Ind 33:251-263. https://doi.org/10.26439 /ing.ind2015.n033.544

Publisher's Note Springer Nature remains neutral with regard to jurisdictional claims in published maps and institutional affiliations. 